\title{
Phenolic Extracts from Meadowsweet and Hawthorn Flowers Have Antioxidative Properties
}

\author{
Zbigniew Sroka* ${ }^{a *}$ Wojciech Cisowski ${ }^{\mathrm{a}}$, Magdalena Seredyńska \\ and Maria Łuczkiewicz ${ }^{\mathrm{b}}$ \\ a Department of Pharmacognosy, Wrocław University of Medicine, pl. Nankiera 1, \\ 50-140 Wrocław, Poland. \\ b Department of Pharmacognosy, Medical University of Gdańsk, Al. Gen. J. Hallera 107, \\ 80-416 Gdańsk, Poland. Fax: 48713442277. E-mail: zbsroka@bf.uni.wroc.pl \\ * Author for correspondence and reprint requests \\ Z. Naturforsch, 56c, 739-744 (2001); received July 13, 2000/April 6, 2001
}

Hawthorn and Meadowsweet Extracts, Antioxidative Activity, Plant Phenolics

From the flowers of meadowsweet and inflorescence of hawthorn the whole set of phenolic acids and flavonoids was analysed by TLC. Phenolic compounds were determined both as free ones and those liberated by hydrolysis. Moreover, ethyl ether and ethyl acetate extracts obtained from the analysed plants before and after alkaline and enzymatic hydrolyses were evaporated under reduced pressure and residues were analysed for their antioxidative properties. The weakest antioxidative activity was observed with the remaining residue after evaporation of ethyl ether extract obtained from enzymatically ( $\beta$-glucosidase) hydrolysed hawthorn inflorescence water extract. The strongest antioxidative activity was noticed with the remaining residues after evaporation of ethyl ether extracts obtained from non-hydrolysed and hydrolysed in alkaline conditions of meadowsweet flower water extracts.

The residues from meadowsweet flowers exhibited stronger antioxidative properties than residues obtained from hawthorn inflorescence and can be recommended as margarine preservatives.

\section{Introduction}

Meadowsweet (Filipendula ulmaria (L.) Maxim.) is a medicinal plant growing in moist meadows, on water banks from north part of Siberia, Altai, Mongolia to the north part of the Balkans, as well as in northern Italy, France, Spain, England and Poland. Its therapeutic features include diaphoretic, anti-rheumatic and anti-inflammatory. Hawthorn (Cratageus oxyacantha L.) is a medicinal plant growing in Europe and North Africa. It is used as a mild, completely non-toxic medicine for heart diseases.

A lot of polyphenolic compounds have been found in both species which can strongly influence their biological activity (Ficcara et al., 1984; Fisel, 1966; Budzianowski et al., 1991; Wagner and Bladt, 1996).

Margarines are fats with highly unsaturated, essential fatty acids, which are known as effective antiarteriosclerotic agents (Worm, 1995; Mortensen et al., 1992). Margarines containing unsaturated fatty acids are very sensitive against many oxidative agents, which may produce toxic sub- stances such as ketones, aldehydes and fatty acid peroxides (Hammer and Wills, 1979; Pokorny et al., 1976; Halliwell and Gutteridge, 1989a). At present manufacturers protect margarines against oxidative processes by adding lipid-soluble substances such as vitamin $\mathrm{E}$ and $\mathrm{A}$ or $\beta$-carotene (van het Hof et al., 1998; Halliwell and Gutteridge, 1989 b). Another group of antioxidants (soluble in water) are plant phenolics such as flavonoids, tannins, catechins or phenolic acids (Halliwell and Gutteridge, 1999; Fauconneau et al. 1997; Benov and Georgiev, 1994; Bahorun et al., 1994; Robak et al., 1986). The therapeutic potential of plant phenolics is continually under study. More data on their clinical efficacy is needed. It is known that flavonoids and their derivatives affect the function of the immune system (Middleton and Kandaswami, 1986). Moreover flavonoids and their derivatives are also known as anti-inflammatory agents. They are considered to reveal vitamin-like activity (Hughes and Wilson, 1977; Kuhnau, 1976), acting on capillary permeability and can be used for the treatment of vascular problems. According to the literature it is encouraging to test plant phenolic 
extracts as possible antioxidant "preservatives" in food.

In this work extracts from hawthorn inflorescence and meadowsweet flowers containing flavonoids and phenolic acids were obtained. These extracts were evaporated under reduced pressure and residues were investigated for their antioxidative properties during margarine oxidation. Moreover, the qualitative analysis of phenolic acids, flavonoids and their glycosides in these extracts was also performed.

\section{Materials and Methods}

\section{Preparation of extracts}

Dried blooms of hawthorn with 2-5 leaves and dried blooms of meadowsweet were used as material. The raw materials ( $75 \mathrm{~g}$ of each species), obtained from Kawon (Herb Factory, 63-800 Gostyń, Poland), after defatting with petroleum ether $(750 \mathrm{ml})$, were extracted three times with $50 \%$ ethanol/water $(3 \times 750 \mathrm{ml})$ by boiling in a water bath. The extracts were stored in a refrigerator for 7 days and then separated from the precipitate formed. Then ethanol was removed under reduced pressure from the combined ethanol/water extracts and the formed precipitate filtered and discarded to obtained water extracts $(1100 \mathrm{ml}$ of each extract) from hawthorn inflorescence (HI) and meadowsweet flowers (MSF).

Two methods of extraction were performed from this step in order to obtain phenolic acids and flavonoid aglycones fraction (method I) and flavonoid glycosides fraction (method II).

Method I. Extracts HI and MSF $(2 \times 820 \mathrm{ml})$ were exhaustively extracted with ethyl ether $(10 \times$ $50 \mathrm{ml}$ - each extract). The pooled ethyl ether extracts were dried under reduced pressure to obtain residues respectively $\mathrm{HA}(0.51 \mathrm{~g})$ and $\mathrm{MA}$ $(0.72 \mathrm{~g})$. The remaining water layer was hydrolysed under alkaline conditions ( $\mathrm{pH} \mathrm{12,1} \mathrm{hr)}$ and extracted with ethyl ether $(8 \times 50 \mathrm{ml}-$ each extract). The ethyl ether extracts were combined and dried under reduced pressure to obtain residues HB $(0.41 \mathrm{~g})$ and MB (0.75 g). The water layers (remaining after alkaline hydrolysis and ethyl ether extraction) were further hydrolysed by $\beta$ glucosidase for $10 \mathrm{hr}$ at $37^{\circ} \mathrm{C}, \mathrm{pH} \mathrm{5.0,}(13 \mu \mathrm{g} / \mathrm{ml}$, Fluka, Switzerland $\sim 6 \mathrm{U} / \mathrm{mg}$ ). The hydrolysates were separated from precipitate formed and sub- sequently extracted with ethyl ether $(10 \times 50 \mathrm{ml}-$ each extract). The pooled ethyl ether extracts were concentrated to dryness under reduced pressure to obtain residues HC (0.22 g), MC (0.41 g).

Method II. Extracts HI and MSF $(2 \times 280 \mathrm{ml})$ were extracted with ethyl acetate $(8 \times 50 \mathrm{ml}-$ each extract). The pooled ethyl acetate extracts were dried under reduced pressure to obtain residues HD (0.31 g), MD (1.35 g).

All residues were further investigated for phenolic compounds composition and antioxidative activity.

\section{Thin layer chromatography}

Residues HA, MA, HB, MB, HC, MC, HD, MD were dissolved in methanol and examined by one dimensional thin layer chromatography on silica gel plates (Merck, Kieselgel $60 \mathrm{~F}_{254}$, DC-Fertigplatten, layer thickness $0.25 \mathrm{~mm}$ ). Phenolic acids and flavonoid aglycones were analysed after migration in toluene-ethyl formate-formic acid, 5:4:1 (Dey and Harborne, 1989a) and isopropyl ethercyclohexane-formic acid, 4:1:0.1 and visualised by spraying with $1 \% \mathrm{FeCl}_{3}$ in methanol, diazotised sulphanilic acid amide (preparation of reagent see below), $0.1 \% \mathrm{AlCl}_{3}$ in methanol and under UV at $365 \mathrm{~nm}$. Flavonoid glycosides were analysed with the solvent acetone-chloroform-water, 8:2:0.48 (Dey and Harborne, 1989b) and visualised by $1 \%$ $\mathrm{AlCl}_{3}$, diazotised sulphanilic acid amide and UV at $365 \mathrm{~nm}$. All phenolic compounds were identified by TLC analysis against standards.

\section{Preparation of diazotised sulphanilic acid amide}

Solution A: $0.5 \mathrm{~g}$ of sulphanilic acid was dissolved in $70 \mathrm{ml}$ of water, $6 \mathrm{ml}$ of $6 \mathrm{~N} \mathrm{HCl}$ was added and adjusted to $100 \mathrm{ml}$ with water. Before use solution A was mixed with $5 \%(\mathrm{w} / \mathrm{v})$ water solution of sodium nitrite in voluminal relation 1:1.

Solution B: $20 \%(\mathrm{w} / \mathrm{v})$ sodium acetate in water.

Plates were developed first with solution A and then with solution $B$.

\section{Measurement of margarine oxidation}

Thiobarbituric acid reagent (TBA) was prepared by dissolving $375 \mathrm{~g}$ of thiobarbituric acid in a small amount of water. Then $15 \mathrm{~g}$ of trichloroacetic acid and $2.1 \mathrm{ml}$ of $10 \mathrm{~N} \mathrm{HCl}$ were added. The solution was adjusted to $100 \mathrm{ml}$ with distilled water. 
The measurement of antioxidative activity was performed by determining TBARS (thiobarbituric acid reactive substances) according to Buege and Aust (1978) modified after Sroka et al. (1994). Margarine containing plant residues as the only antioxidative agent was prepared in our laboratory according to the method of Sroka and Cisowski (1999).

Six samples of margarines were prepared - one with no plant residue (control sample) and five with $0.002,0.008,0.03,0.1$ and $0.5 \%(w / w)$ residue (HA, MA, HB, MB, HC, MC, HD and MD) in solid margarine. The margarine peroxidation was induced by ultraviolet radiation UV at $254 \mathrm{~nm}-$ bactericidal lamp intensity $80 \mu \mathrm{W} / \mathrm{cm}^{2}$. The margarines were sampled after $0,3,6$ and $9 \mathrm{~h}$ of UV exposure. Then the samples were dissolved in ethyl ether at the concentration of $0.17 \mathrm{mg} / \mathrm{ml}$. $1 \mathrm{ml}$ of ethyl ether solution of each sample was evaporated under nitrogen and $2 \mathrm{ml}$ of TBA reagent added. All samples were put into a boiling water bath for $20 \mathrm{~min}$, then centrifuged for $5 \mathrm{~min}$ at $1000 \times g$ and the supernatant was measured at $535 \mathrm{~nm}$.
All measures were repeated three times and standard deviations were calculated approximately 0.05 .

\section{Results and Discussion}

The whole set of phenolic acids and flavonoids identified in our experiments in HI and MSF extracts are demonstrated in Tables I and II. The TLC qualitative analysis fully confirmed literature data on the presence of a rich set of phenolic compounds in the analysed plant materials.

Hawthorn inflorescence contain many quercetin derivatives such as quercetin 3-galactoside (hyperoside) (Ficcara et al., 1984), quercetin 3-rutinoside (rutin) (Fisel, 1966), quercetin 3-glucoside (isoquercitrin) (Bahorun et al., 1994), quercetin 3-rhamnogalactoside (Fisel, 1966), kaempferol and its derivatives (Nikolov et al., 1982), luteolin, apigenin (Ficcara et al., 1990a) and their C-glycosides such as apigenin 8-C glycoside (vitexin), isovitexin (Budzianowski et al., 1991). Among other simple phenolic compounds chlorogenic (Ficcara et al., 1984), caffeic (Ficcara et al., 1990b) and gallic (Bahorun et al., 1994) acids were identified.

Table I. Phenolic acids identified in residues obtained from hawthorn inflorescence and meadowsweet flowers.

\begin{tabular}{|c|c|c|c|c|c|c|}
\hline \multirow[b]{2}{*}{ Identified compound } & \multicolumn{3}{|c|}{$\begin{array}{l}\text { Hawthorn } \\
\text { inflorescence residues }\end{array}$} & \multicolumn{3}{|c|}{$\begin{array}{l}\text { Meadowsweet } \\
\text { flower residues }\end{array}$} \\
\hline & HA & $\mathrm{HB}$ & $\mathrm{HC}$ & MA & MB & $\mathrm{MC}$ \\
\hline Protocatechuic & + & + & + & + & + & + \\
\hline Caffeic & + & + & + & + & + & + \\
\hline Chlorogenic & + & + & + & - & - & - \\
\hline Salicylic & + & + & - & + & + & + \\
\hline Gallic & + & + & + & + & + & + \\
\hline p-Hydroxybenzoic & + & + & + & - & - & - \\
\hline$m$-Hydroxybenzoic & - & - & - & + & - & - \\
\hline 2,3-dihydroxybenzoic & + & - & + & + & + & + \\
\hline 3,5-dihydroxybenzoic ( $\alpha$-resorcylic) & - & - & - & + & + & - \\
\hline 2,4 -dihydroxybenzoic ( $\beta$-resorcylic) & + & + & - & - & - & - \\
\hline Veratric & + & + & + & - & + & + \\
\hline Ferulic & + & + & + & + & + & + \\
\hline Vanillic & - & - & - & + & - & - \\
\hline Syringic & + & + & + & - & - & - \\
\hline$p$-Coumaric & - & + & + & + & + & - \\
\hline$o$-Coumaric & + & + & + & + & - & - \\
\hline$m$-Coumaric & + & - & - & - & - & - \\
\hline Rosmarinic & + & + & - & - & - & - \\
\hline Elagic & + & - & + & - & + & + \\
\hline
\end{tabular}

Legend: (+) compound present; (-) compound absent.

Abbreviations: HA, MA, HB, MB, HC, MC stand for residues after reduced pressure evaporation of ethyl ether extracts obtained from hawthorn inflorescence (HI) and meadowsweet flowers (MSF) water extracts, alkaline hydrolysis HI and MSF and enzymatically hydrolysed HI and MSF respectively. 
Table II. Flavonoids identified in residues obtained from hawthorn inflorescence and meadowsweet flowers.

\begin{tabular}{llllllllll}
\hline \multirow{2}{*}{ Identified compound } & \multicolumn{3}{c}{ Hawthorn inflorescence residues } & \multicolumn{3}{c}{ Meadowsweet flower residues } \\
& HA & HB & HC & HD & MA & MB & MC & MD \\
\hline Quercetin & + & + & + & - & + & + & + & - \\
Hyperoside (quercetin-3-galactoside) & - & - & - & + & - & - & - & + \\
Luteolin & + & + & + & - & + & + & + & - \\
Kaempferol & + & + & + & - & + & + & + & - \\
Vitexin & - & - & - & + & - & - & - & - \\
Isovitexin & - & - & - & + & - & - & - & - \\
Avicularin (quercetin-3-arabinoside) & - & - & - & + & - & - & - & + \\
Apigenin & + & + & + & + & + & + & - & - \\
Myricetin & - & - & - & - & + & + & + & - \\
Rutin (quercetin-3-rutinoside) & - & - & - & + & - & - & - & + \\
Quercetin-3-rhamnogalactoside & - & - & - & + & - & - & - & - \\
\hline
\end{tabular}

Legend: (+) compound present; (-) compound absent.

Abbreviations: HA, MA, HB, MB, HC, MC stand for residues after reduced pressure evaporation of ethyl ether extracts obtained from hawthorn inflorescence (HI) and meadowsweet flowers (MSF) water extracts, alkaline hydrolysis HI and MSF and enzymatically hydrolysed HI and MSF respectively. HD, MD denotes residues after evaporation of ethyl acetate extracts obtained from HI and MSF.

Phenolic contents identified in meadowsweet flowers are flavonoids (3-5\%) mainly spiraeoside (Pouknes-Renwart, 1992), quercetin, hyperoside, avicularin, rutin, kaempferol and their glycosides (Wagner and Bladt, 1996). Important simple phenolics identified in meadowsweet flowers are derivatives of salicylic alcohol, aldehyde and acid (Hegnauer, 1973).

Our TLC analysis showed the presence of quercetin and its derivatives which are one of the strongest antioxidants among flavonoids in $\mathrm{HI}$ extract. Strongly antioxidative phenolic acids such as gallic, caffeic, chlorogenic were also observed in HI.

Myricetin (strong antioxidant) which was not yet mentioned in literature was determined in MSF extract. Among phenolic acids with strong antioxidative properties gallic, caffeic, chlorogenic, and protocatechuic acids were identified too.

The results of our phytochemical analyses (Tables I and II), together with literature reports indicate that selected HI and MSF extracts may be considered for use as antioxidants in margarine.

The oxidation results, expressed as absorbance at $535 \mathrm{~nm}$, for margarine containing $\mathrm{HA}, \mathrm{HB}, \mathrm{HC}$ and HD residues are demonstrated in Table III, while MA, MB, MC and MD residues are demonstrated in Table IV.

The HA residue only weakly inhibited oxidation at maximal concentration of $0.5 \%$. HB residue in- hibited the oxidation process weakly at $0.1 \%$ and strongly at $0.5 \%$. HC residue was a poor antioxidant, no inhibition of oxidation of margarines was observed in concentrations of 0.1 and $0.5 \%$ of this residue. HD residue stimulated the oxidation process at $0.002,0.008$ and $0.03 \%$. There was no effect at the concentration of $0.1 \%$ and strong inhibition was observed at $0.5 \%$ of HD.

The MA residue did not influence oxidation at the concentration of $0.002,0.03 \%$, and it increased margarine oxidation at $0.008 \%$. At the concentration of 0.1 and $0.5 \%$ this residue caused strong inhibition of the oxidation process. MB residue stimulated margarine oxidation strongly at $0.002 \%$ and weakly at 0.008 and $0.03 \%$. At 0.1 and $0.5 \%$ almost complete inhibition was observed. When $\mathrm{MC}$ was investigated, the stimulation of the oxidation process was observed at $0.002,0.008,0.03$ and $0.1 \%$. However, only at $0.5 \%$ weak oxidation of margarine was observed. MD residue did not influence oxidation at $0.002,0.03 \%$, while strong oxidation inhibition took place at $0.1 \%$ and $0.5 \%$, respectively.

Our results show a stronger effect of oxidation inhibition when residues obtained from MSF were used. These extracts can be recommended as antioxidants effective in margarine. Residues obtained from HI appear to be weak antioxidant agents but they may be very useful as margarine additives to prevent arteriosclerosis and heart diseases. 


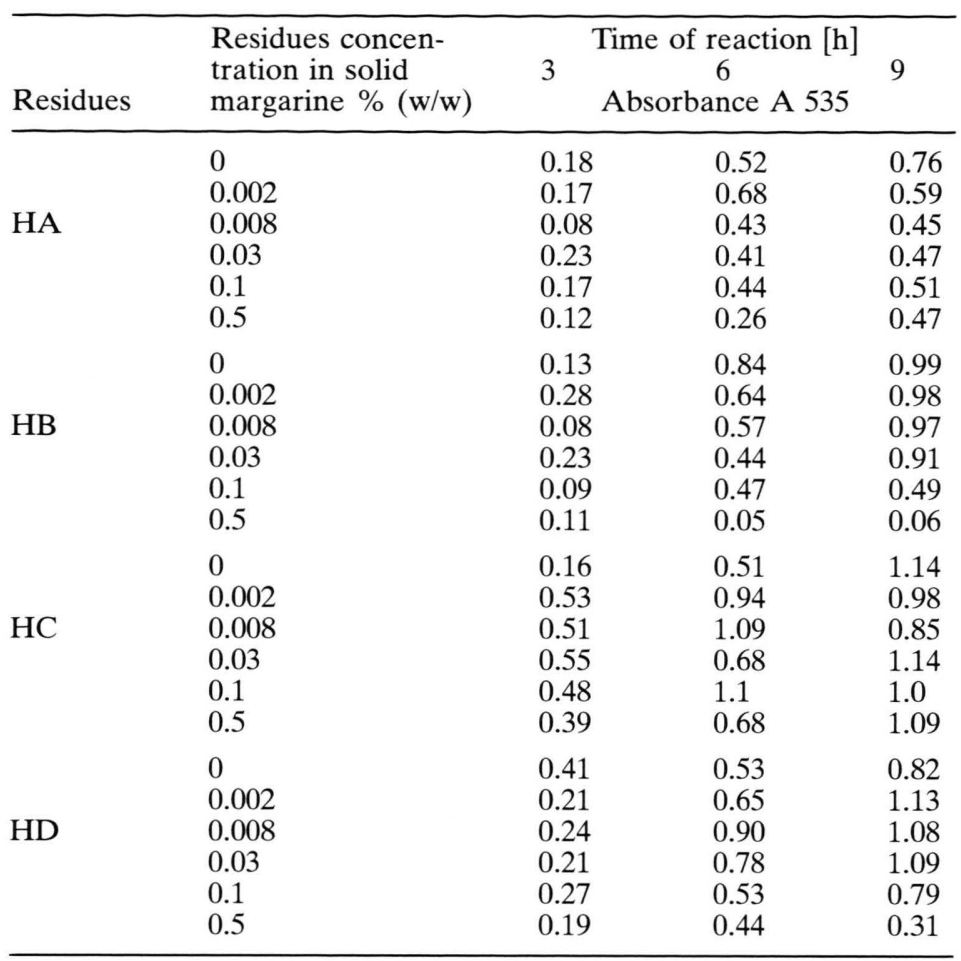

Table III. Margarine oxidation in the presence of residues obtained from hawthorn inflorescence.

Abbreviations: HA, HB, HC stand for residues after reduced pressure evaporation of ethyl ether extracts obtained from hawthorn inflorescence water extract (HI); alkaline hydrolysed HI and enzymatically hydrolysed $\mathrm{HI}$ respectively. HD denotes residues after evaporation of ethyl acetate extract obtained from HI.

\begin{tabular}{|c|c|c|c|c|}
\hline Residues & $\begin{array}{l}\text { Residues concen- } \\
\text { tration in solid } \\
\text { margarine } \%(w / w)\end{array}$ & 3 & $\begin{array}{c}\text { Time of reaction }[\mathrm{h}] \\
6 \\
\text { Absorbance A } 535\end{array}$ & 9 \\
\hline MA & $\begin{array}{l}0 \\
0.002 \\
0.008 \\
0.03 \\
0.1 \\
0.5\end{array}$ & $\begin{array}{l}0.22 \\
0.20 \\
0.32 \\
0.09 \\
0.06 \\
0.06\end{array}$ & $\begin{array}{l}0.40 \\
0.66 \\
0.83 \\
0.57 \\
0.10 \\
0.12\end{array}$ & $\begin{array}{l}0.73 \\
0.60 \\
0.80 \\
0.61 \\
0.09 \\
0.03\end{array}$ \\
\hline MB & $\begin{array}{l}0 \\
0.002 \\
0.008 \\
0.03 \\
0.1 \\
0.5\end{array}$ & $\begin{array}{l}0.22 \\
0.23 \\
0.40 \\
0.26 \\
0.06 \\
0.06\end{array}$ & $\begin{array}{l}0.41 \\
0.79 \\
0.76 \\
0.52 \\
0.11 \\
0.06\end{array}$ & $\begin{array}{l}0.73 \\
1.27 \\
0.67 \\
0.84 \\
0.16 \\
0.06\end{array}$ \\
\hline $\mathrm{MC}$ & $\begin{array}{l}0 \\
0.002 \\
0.008 \\
0.03 \\
0.1 \\
0.5\end{array}$ & $\begin{array}{l}0.45 \\
0.36 \\
0.30 \\
0.30 \\
0.08 \\
0.14\end{array}$ & $\begin{array}{l}0.58 \\
0.78 \\
0.86 \\
0.46 \\
0.55 \\
0.07\end{array}$ & $\begin{array}{l}0.74 \\
0.98 \\
1.29 \\
1.12 \\
1.10 \\
0.23\end{array}$ \\
\hline MD & $\begin{array}{l}0 \\
0.002 \\
0.008 \\
0.03 \\
0.1 \\
0.5\end{array}$ & $\begin{array}{l}0.15 \\
0.43 \\
0.12 \\
0.23 \\
0.06 \\
0.06\end{array}$ & $\begin{array}{l}0.91 \\
0.68 \\
1.04 \\
0.86 \\
0.27 \\
0.21\end{array}$ & $\begin{array}{l}1.03 \\
1.04 \\
1.24 \\
1.01 \\
0.36 \\
0.32\end{array}$ \\
\hline
\end{tabular}

Table IV. Margarine oxidation in the presence of residues from meadowsweet flowers.

Abbreviations: MA, MB, MC stand for residues after reduced pressure evaporation of ethyl ether extracts obtained from meadowsweet flowers water extract (MSF); alkaline hydrolysed MSF and enzymatically hydrolysed MSF respectively. MD denotes residues after evaporation of ethyl acetate extract obtained from MSF. 
Bahorun T., Trotin F., Pommery J., Vasseur J. and Pinkas M. (1994), Antioxidant activities of Crataegus monogyna extracts. Planta Med. 60, 323-328.

Benov L. and Georgiev (1994), The antioxidant activity of flavonoids isolated from Corylus colurna. Phytother. Res., 8, $92-94$.

Budzianowski J., Palulski G. and Robak J. (1991), Studies on antioxidative activity of some C-glycosylflavones. Pol. J. Pharmacol. Pharm. 43, 395-401.

Buege J.-A. and Aust S.-D. (1978), Microsomal lipid peroxidation. Methods Enzymol. 52C, 302-310.

Dey P. M. and Harborne J. B. (1989b), Flavanoids. In: Methods in Plant Biochemistry, Plant Phenolics (J. B. Harborne, ed.). Academic Press, London, pp. 283323.

Dey P. M. and Harborne J. B. (1989a), Phenols and phenolic acids. In: Methods in Plant Biochemistry, Plant Phenolics (J. B. Harborne, ed.). Academic Press, London, pp. 29-73.

Fauconneau B., Waffo-Teugo P., Huguet F., Barrier L., Decendit A. and Merillon J.-M. (1997) Comparative study of radical scavenger and antioxidant properties of phenolic compounds from Vitis vinifera cell cultures using in vitro test. Life Sci. 61, 2102-2110.

Ficcara P., Ficcara R., De Pasquale A., Monforte M. T., Calabro M. L. (1990a), High-performance liquid chromatography of flavonoids in Crataegus oxyacantha L. IV. Reversed-phase high-pressure liquid chromatography in flower, leaf and bud extractives of Crataegus oxyacantha L. Farmaco. 45, 247-255.

Ficcara P., Ficcara R., Tommasini A., De Pasquale A., Guarniera Fenech C., Iauk L. (1984) Analysis of 2-phenyl-chromon derivatives and chlorogenic acid. II. High-performance thin layer chromatography and high-performance liquid chromatography in flowers, leaves and buds extractives of Crataegus oxyacantha L. Farmaco. 39, 342-354.

Ficcara P., Ficcara R., Villari A., De Pasquale A., Monforte M. T. and Calabro M. L. (1990b), High-performance liquid chromatography and diffuse reflectance spectroscopy of flavonoids in Crataegus oxyacantha $\mathrm{L}$. III. Analysis of 2-phenyl-chroman derivatives and caffeic acid. Farmaco. 45, 237-245.

Fisel J. (1966) Neue Flavonoide aus Crataegus. 2. Die Isolierung eines Gemisches aus Rutin und Quercetin3-rhamnogalaktosid aus Crataegus monogyna L. Arzneimittelforsch. 16, 323-328.

Halliwell B. and Gutteridge J.-M.-C. (1989a), Lipid peroxidation: a radical chain reaction. In: Free Radical in Biology and Medicine (B. Halliwell and J. M. C. Gutteridge, eds.). Oxford University Press, Oxford, pp. $188-276$.

Halliwell B. and Gutteridge J.-M.-C. (1989b), Protection by "antioxidants": general principles. In: Free Radical in Biology and Medicine (B. Halliwell and J. M. C. Gutteridge, eds.). Oxford University Press, Oxford, pp. 236-237.

Halliwell B. and Gutteridge J.-M.-C. (1999), Plant phenols. In: Free Radicals in Biology and Medicine (B. Halliwell and J. M. C. Gutteridge, eds.) Oxford University Press, Oxford 1999, pp. 225-245.
Hammer C.-T. and Wills E.-D. (1979), The effect of ionizing radiation on the fatty acid composition of natural fats and on lipid peroxide formation. Int. J. Radiat. Biol. Relat. Stud. Phys. Chem. Med. 35, 323-332.

Hegnauer R. (1973) Rosoidae. In: Chemotaxonomie der Pflanzen (R. Hegnauer, ed.) Birkhäuser Verlag, Basel und Stuttgart, vol. 6, pp. 104-105.

van het Hof K.-H., Tijburg L. B., de Boer H. S., Wiseman S. A. and Weststrate J. A. (1998), Antioxidant fortified margarine increases the antioxidant status. Eur. J. Clin. Nutr. 52, 292-299.

Hughes R.-E. and Wilson H.-K. (1977), Flavonoids: some physiological and nutritional considerations. Prog. Med. Chem. 14, 285-301.

Kuhnau J. (1976) The flavonoids. A class of semi-essential food components: their role in human nutrition. World Rev. Nutr. Diet. 24, 117-191.

Middleton E. and Kandaswami C. (1986), The impact of plant flavonoids on mammalian biology: implication for immunity, inflammation and cancer. In: The Flavonoids (Harborne J. B., ed.). Chapman \& Hall, London, Glasgow, New York, Tokyo, Melbourne, Madras, pp. 619-652.

Mortensen A., Espensen P.-L., Hansen B.-F. and Ibsen P. (1992) The influence of dietary olive oil and margarine on aortic cholesterol accumulation in cholesterolfed rabbits maintained at similar plasma cholesterol level. Atherosclerosis 96, 159-170.

Nikolov N., WagnerH., Chopin J., Dellamonica G., Chari V. M. and Seligmmann (1982), Recent investigations of Crataegus flavonoids. In: Flavonoids and Bioflavonoids (Farkas L., Gabor M., Kallay F. and Wagner H., eds.). Elsevier Scientific Publishing Company, Amsterdam, Oxford, New York, pp. 325-344.

Pokorny J., El-Zeany A., Nguyen-thien L. and Janicek G. (1976), Nonenzymic browning. XV. Effect of unsaturation on browning reactions of oxidized lipids with protein. Z. Lebensm. Unters. Forsch. 161, 271-272.

Pouknes-Renwart P., Tits M., Wauters J. N. and Angenot L. (1992), Densitometric evaluation of spiraeoside after derivatization in flowers of Filipendula ulmaria (L.) Maxim. J. Pharm. Biomed. Anal. 10, 1085-1088.

Robak J., Duniec Z., Rzadkowska-Bodalska H., Olechnowicz-Stepień W. and Cisowski W. (1986), The effect of some flavonoidson-nonenzymatic lipid oxidation and enzymatic oxidation of arachidonic acid. Pol. J. Pharmacol. Pharm. 38, 483-491.

Sroka Z., Cisowski W. (1999) Resistance of solid lipids on oxidation. Polish Patent P-336731.

Sroka Z., Rzadkowska-Bodalska H. and Mażol I. (1994), Antioxidative effect of extracts from Erodium cicutarium L. Z. Naturforsch. 49c, 881-884.

Wagner H. and Bladt S. (1996) Flavonoid drugs including Ginkgo biloba and Echinaceae species. In: Plant Drug Analysis. A Thin Layer Chromatography Atlas (H. Wagner and S. Bladt, eds.) Springer-Verlag, Berlin, pp. $195-244$.

Worm N. (1995), Nutrition heart disease: how important is diet? Versicherungsmedizin 47, 116-122. 